\title{
Phytochemical Analysis and Antifungi Activity of Aloe Vera Leaves
}

\author{
${ }^{1}$ Ikpe, V., ${ }^{2}$ Eze, C. S., ${ }^{1} \mathrm{Mbaoji}$, P. and ${ }^{3} J o s h u a$, P. E. ${ }^{*}$ \\ ${ }^{1}$ Department of Biochemistry, Caritas University, Enugu, Nigeria \\ 2Department of Applied Biology and Biotechnology, Enugu State University of Science and Technology, \\ Enugu, Enugu State. Nigeria \\ ${ }^{3}$ Department of Biochemistry, University of Nigeria, Nsukka, Nigeria \\ *Corresponding Author:- parker.joshua @unn.edu.ng; Tel.No +2348037804687
}

\begin{abstract}
The medicinal and other claimed uses of Aloe vera, the "wonder plant", are endless. The extract for phytochemical analysis was collected in three different solvents, diethyl ether, ethanol and distilled water. The anti-fungal activities of the leaf extract were investigated on selected fungi organisms; Trycophytum rubrum, Penicillum notatum, Trycophytum vericophytum, Trycophytum soundanense, Claudosporium and Trycophytum mentagrophytis collected from Mycology Laboratory, University of Nigeria Teaching Hospital, Enugu, Nigeria. The plant extract was collected crude without solvent and agar-well diffusion method employed for the determination of antifungal activities on the test organisms using $200 \mathrm{mg}$ ketoconazole drug as standard. The phytochemical constituents of aloe vera leaf include alkaloids, flavonoids, saponin, phenol, glycosides and tannins. Both undiluted and half diluted crude extract showed different zones of inhibition on the test organisms. The undiluted crude extract of Aloe vera had larger zone of inhibition on Trycophytum rubrum and Trycophytum mentagrophytis than the diluted crude extract while the diluted crude extract showed larger zone of inhibition on Trycophytum vericopytum than the undiluted crude extract.
\end{abstract}

Key words: Aloe vera, Phytochemicals, Constituents, Antifungal properties.

\section{INTRODUCTION}

Aloe vera, sometimes described as a "wonder plant", is a short stemmed succulent shrub growing to $60-100 \mathrm{~cm}$ (24-39 inch) tall and spreading by offsets. The leaves are thick and fleshy, green to grey-green with some varieties showing white flecks on the upper and lower stem surface (Yates, 2003). The flowers are produced in summer on a spike up to $90 \mathrm{~cm}$ (35 inch) tall, each flower being pendulous with a yellow tubular corolla $2-3 \mathrm{~cm}$ (0.8 $1.2 \mathrm{inch}$ ) long. The name Aloe is derived from the Arabic word "Alloeh", meaning shining bitter substances while Vera means "true". Like other Aloe spices, Aloe vera forms arbuscular mycorrhiza, a symbiosis that allows the plant better access to mineral nutrients in soil (Gong et al., 2002). Some related Aloes occur naturally in North Africa (Bibsy et al., 2007) but is widely cultivated throughout the world and largescale agricultural production is undertaken in Australia, Bangladesh, Cuba, the Dominican Republic, China, Mexico, India, Jamaica, Kenya, Tanzania and South African along with the united states of America to supply the Cosmetic industry with Aloe vera gel (United States Department of
Health and Human Services, 2010). Aloe vera produces two substances, gel and latex. Aloe gel is the clear, jelly- like Substances found in the inner part of the Aloe plant leaf. Aloe latex comes from the plant's skin and is yellow in colour.

Phytochemicals are plant chemicals that protect them against bacteria and viruses. The action of phytochemicals varies by colour and type of food. They may act as antioxidants or nutrient protectors or prevent carcinogens (Hazra et al., 2008). A fungus is any member of a large group of eukaryotic organisms that includes microorganisms such as yeasts and molds as well as the more familiar mushrooms. These organisms are classified as a kingdom, which is separate from plants, animals, protists and bacteria. The cell walls of fungal cells contain chitin unlike the cell walls of plants and some protists that contain cellulose and also different from the cell walls of bacteria.

\section{Rational of Study}

The medicinal and other claims associated with Aloe vera are endless. This plant has been used 
for centuries for health, beauty, medicinal and skIn care (Gupta et al., 2012). Alexander the great and Christopher Columbus used it to treat soldiers' wounds (Cazander et al., 2012). Other therapeutic claims of aloe Vera include teeth and gum treatment, constipation treatment, healing of diabetes induced foot ulcers, antioxidant and antimicrobial properties and protection from irradiation (Boudreu, 2006). Aloe vera is also used commercially as an ingredient in yogurts, beverages, and some deserts (Raynolds, 2004). Uses of extracts of aloe vera include the dilution of semen for fertilization of sheep (Rodriguez et al., 2008), as a fresh food preservative or for water conservation in small farms (Shukla, 2008). Scientific evidence for the cosmetic and therapeutic effectiveness of aloe vera is limited and when present is frequently contradictory (Ernest, 2000).Thus the aim of this study was to assess the phytochemical constituents of aloe vera and also to ascertain if aloe vera has antifungal activities.

\section{MATERIALS AND METHODS}

The Aloe Vera plant was identified by Prof. C. E. A. Okezie, Former Head of Department, Plant Science \& Biotechnology, University of Nigeria, Nsukka. The leaves were sliced and pounded with pestle and mortar. Five grams (5 g) each were weighed into three different $250 \mathrm{ml}$ conical flasks, $5 \mathrm{ml}$ of diethyl either was added to flask $\mathrm{A}, 5 \mathrm{ml}$ of ethanol to flask $B, 5 \mathrm{ml}$ distilled water to flask $C$ and the three flasks corked. The leaves were soaked in these solvents for $24 \mathrm{hrs}$, decanted and heated to concentrate the extract used to test for the presence of alkaloid, saponin, flavonoid, steroid, tannins, phenol and glycosides.

The crude aloe vera extract used for the antifungal study, was obtained by cutting off a healthy leaf at the point of attachment to the stem and with a sharp knife the leaf was peeled along the spiked side and sliced open along the same side rendering the leaf in two halves along its length. With a clean spoon, the gel was scraped into a clean container and blended. Stock cultures of Trycophytum rubrum, penicillum notatum, Trychophytum Verichophytum,

Trycophytum soudanense, Claudosporium and Trycophytum mentagrophytis were obtained from Mycology laboratory, University of Nigerian Teaching Hospital, Enugu, and grown on sabouraud dextrose agar for one week at room temperature for pure cultures. Antifungal activity was carried out with the overnight peptone broth culture of the fungi organisms on six different sabouraud agar plates layered with $0.5 \%$ actidion (cyclohexamide) and allowed to stand for $2 \mathrm{hrs}$ after which four holes were bored on each agar plate for the single and double dilutions of $200 \mathrm{mg}$ ketoconazole used as standards and for whole and half diluted aloe vera extracts. The plates were kept in an upright position and incubated for $24 \mathrm{hrs}$ at $28^{\circ} \mathrm{C}$. The diameter of the zones of inhibition was measured with a transparent meter rule in millimeters $(\mathrm{mm})$.

\section{RESULTS}

\section{Qualitative Phytochemical (Identification) Constituents of Aloe Vera}

Table 1 shows qualitative phytochemical constituents of Aloe vera leaves. Bioactive constituents such as phenols and glycosides were found to be abundantly present in ethanol extracted sample as compared to other solvents while steroids were not detected in all the solvent samples as observed in Table 1. The presence of flavonoids were detected to be moderate in diethyl ether and ethanol while phenols were detected in moderate abundance in diethyl ether and aqueous samples. Other the other hand, tannins were not detected in ethanol and aqueous samples but detected slightly in diethyl ether. Relative slight presence was observed for alkaloids in all solvent samples under investigation.

Table 1: Qualitative phytochemical (identification) constituents of Aloe vera

\begin{tabular}{llll}
\hline PARAMETERS & \multicolumn{3}{c}{ SOLVENTS } \\
\cline { 2 - 4 } & $\begin{array}{c}\text { Diethyl } \\
\text { ether }\end{array}$ & Ethanol & Water \\
\hline Alkaloids & + & + & + \\
Saponins & ++ & + & + \\
Flavoniods & ++ & ++ & + \\
Steroids & - & - & - \\
Tannins & + & - & - \\
Phenols & ++ & +++ & ++ \\
Glycosides & ++ & +++ & + \\
\hline
\end{tabular}

$\begin{array}{ll}\text { Key } & +=\text { Slightly present } \\ += & \text { Moderately present } \\ +++ & =\text { Largely present } \\ \text { ND } & =\text { Not detected }\end{array}$


Antifungal activity of Aloe Vera Showing Diameter of Zones of Inhibition Against Test Organisms

Table 2 shows antifungal activity of aloe vera showing diameter of zones of inhibition against test organisms. The result as expressed in Table 2 showed no effect on Trycophytum verichophytum, Trycophytum soudanense and Trycphytum mentagrophytis in both $200 \mathrm{mg}$ of single and double dilution of ketoconazole compared to that of the aloe vera samples that showed effect. On the other hand, no effect was observed on Penicillum notatum, and Claudosporium in the aloe vera treated samples while effects were observed in the standard. The effect on the zone of inhibition was observed in Trycophytum rubrum across both the standard and the test samples (aloe vera). Generally, no effect was observed on Trycophytum soudanense across the standard and the test.

\begin{tabular}{|c|c|c|c|c|}
\hline \multirow[t]{3}{*}{ Test organisms } & \multicolumn{4}{|c|}{ Zone of Inhibition } \\
\hline & \multicolumn{2}{|c|}{ Standard } & \multicolumn{2}{|c|}{ Sample(aloe vera leaf) } \\
\hline & \begin{tabular}{c}
\multicolumn{1}{c}{$200 \mathrm{mg}$} \\
Ketoconazole \\
single dilution
\end{tabular} & \begin{tabular}{l}
\multicolumn{1}{c}{$200 \mathrm{mg}$} \\
Ketoconazole \\
double dilution
\end{tabular} & $\begin{array}{c}\text { Crude Aloe } \\
\text { Vera extract(undiluted) }\end{array}$ & $\begin{array}{l}1 / 2 \text { dilution } \\
\text { Of crude } \\
\text { extract }\end{array}$ \\
\hline Trycophytum rubrum & $157.5 \mathrm{~mm}$ & $110 \mathrm{~mm}$ & $80 \mathrm{~mm}$ & $43.3 \mathrm{~mm}$ \\
\hline Penicillum notatum & $77.5 \mathrm{~mm}$ & $95 \mathrm{~mm}$ & No effect & No effect \\
\hline $\begin{array}{l}\text { Trycophytum } \\
\text { verichophytum }\end{array}$ & No effect & No effect & $43.3 \mathrm{~mm}$ & $172.5 \mathrm{~mm}$ \\
\hline $\begin{array}{l}\text { Trycophytum } \\
\text { soudanense }\end{array}$ & No effect & No effect & No effect & No effect \\
\hline Claudosporium & $90 \mathrm{~mm}$ & $40 \mathrm{~mm}$ & No effect & No effect \\
\hline $\begin{array}{l}\text { Trycphytum } \\
\text { mentagrophytis }\end{array}$ & No effect & No effect & $232.5 \mathrm{~mm}$ & $100 \mathrm{~mm}$ \\
\hline
\end{tabular}

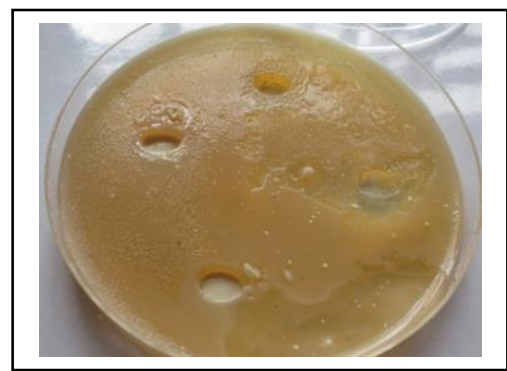

Trycophytum vericophytum

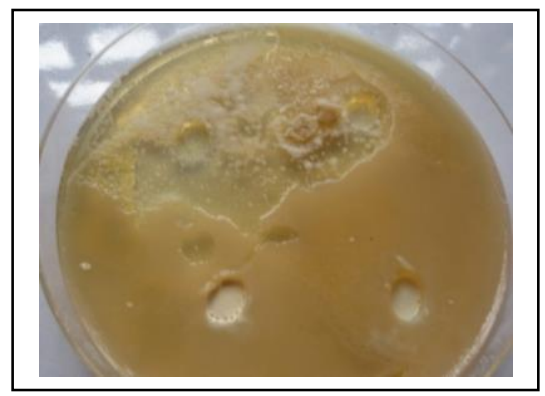

Trycophytum mentagrophytis

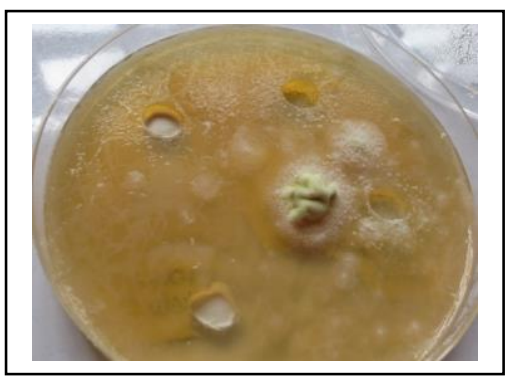

Trycophytum Soudanense

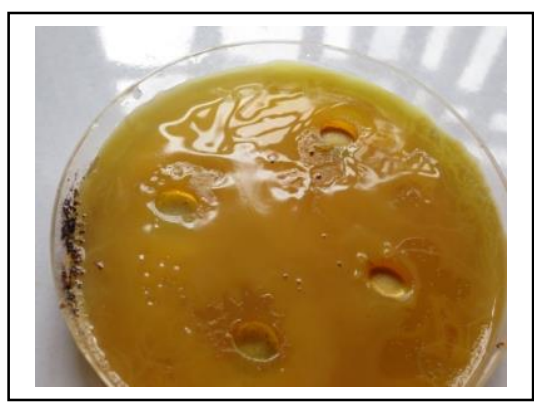

Trycophytum rubrum

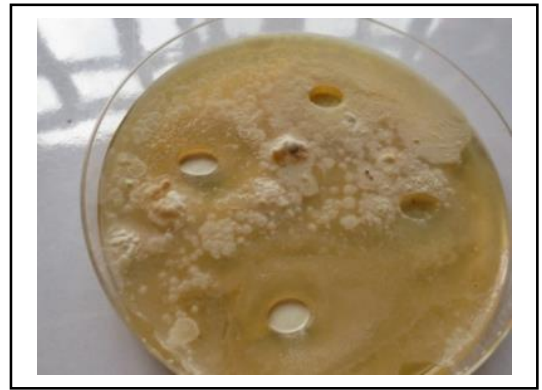

Claudosporium

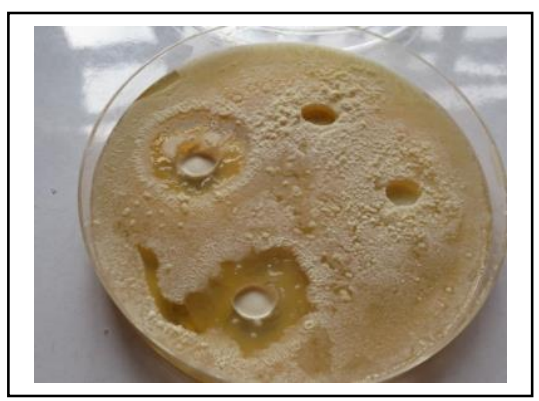

Penicillium notatum 


\section{DISCUSSION}

African plants have been investigated for their chemical constituents and some of the isolated compounds have been shown to posses interesting biological activities while some species still remain uninvestigated (Coleby- willians etal., 2008). In Nigeria, almost all plants are medicinal and medicine is currently acknowledged and established as a viable profession (Feroogi, 2004). Plants have an almost limitless ability to synthesize aromatic substances which serve as plant defense mechanism against predation by microorganisms, insects and herbivores. Some such as terpenoids give plants their odour, others (guinnes and tannins) are responsible for plant pigments while many others are responsible for plant flavour like the hepenoids capsaicin from chilli pepper.

Phytochemical compounds play important roles in the bioactivity of medicinal plants. Our qualitative analysis of aloe vera leaf revealed the presence of alkaloid, flavonoid, saponin, phenol, glycoside and tannin.

Alkaloids are made largely of ammonium compounds comprising basically nitrogen bases synthesized from amino acid building blocks with various radicals replacing one or more of the hydrogen atoms in the peptide ring, mostly containing oxygen. Majority of alkaloids exist in solid such as atropine, some as liquids containing carbon, hydrogen and nitrogen (Atherton, 2007). These nitrogenous compounds function in the defense of plants against herbivores and pathogens and are widely exploited as pharmaceuticals, stimulants, narcotics and poisons due to their potent biological activities (Samaica, 2010). Flavonoids are important group of polyphenols widely distributed among the plant flora, made of more than one benzene ring and derived from the parent compound flavans. Over four thousand flavonoids are known to exist and some of them are pigments in higher plants. Quercetin, kaempferol, calchones and catechin are common flavonaids present in nearly $70 \%$ of plants (Henry, 2007). They have the ability to scavenge for hydroxyl radicals and superoxide anions and thus health promoting in action (Heinrich et al., 2008).Saponin is derived from Saponariavaccaria, a plant which abounds in Saponins and used as soap. Saponins, therefore possess 'soaplike' behaviour in water, that is, they produce foam. On hydrolysis, an aglycone, called Saprogenin is produced.
Phenolics, phenols, polyphenolics or polyphenol extracts are chemical compound that occur ubiquitously as natural colour Pigments responsible for the colour of fruits of plants. Phenolics in plants are mostly synthesized from phenylalanine via the action of phenylalanine ammonia lyase. The most important role may be in plant defense against pathogens and herbivore predators and thus applied in the control of human pathogenic infections (Vaibhar, 2008).

Glycosides are the condensation products of sugars including polysaccharides with a host of different varieties of organic hydroxyl compounds invariably monohydrate in character. They are colourless, water soluble phytoconstituents that contain a carbohydrate (glucose) and a noncarbohydrate (aglycone or genin) (Marshal, 2010).

Tannins constitute phenolic compounds of high molecular weight and widely distributed in plant flora. They have a characteristic feature to tan, that is, to convert materials into leather. Tannins are divided into hydrolysable tannins and condensable tannins. Hydrolysable tannins are called gallotannins or egallitannis and on hydrolysis, produce gallic acid and ellagic acid. Tannins are used as antiseptic due to the presence of the phenolic group and tannin-rich medlcinal plants are used as healing agents in a number of diseases like leucorrhoea, rhinnorhoea and diarrhea (Leung and Fosters, 2009).

Fungi are the principal decomposers in every ecosystem and are composed of filaments called hyphae which become specialized for penetrating the cells of the host (Ginseng, 2012). Fungi organisms that cause skin irritations and chopping of fingers in humans were subjected to the activity of aloe vera extract. The extract was sensitive to some fungi organisms and could be used for treatment. Crude extract of aloe vera can be used to treat infections from Trychopytum vericophytum, Trychophytum mentagrophytis and Trychophytum rubrum (Figure 1).

In our society, many fruits, spices, herbs, and leafy vegetables used as food and medicinal purposes are obtained from the wild where there may be as many as a thousand species. Till date, little attempt has been made to identify, domesticate and cultivate these plants despite the fact that they constitute large proportion of the daily diet of rural dwellers. The implication of this, is that several of these plants could become extinct due to deforestation and reluctance to 
venture into the forest to harvest them. Traditional and orthodox medicine practitioners should be encouraged to adopt the use of plants in the treatment of certain infections and diseases caused by microorganisms while the pharmaceutical industry should incorporate plant extracts in the production of drugs.

\section{Conflict of Interest}

There is no conflict of interest regarding the manuscript.

\section{REFERENCES}

Atherton, P. (2007). The Essentials of Aloe Vera: The actions and the evidence. Journal of the American Chemical Society, 125 (22): $6632-6633$.

Bibsy, F.A., Roskov, Y.A., and Ruggerio, $M$ (2007). Species 2000 and its catalogue of life. Journal of Nutrition B1:2837-2842.

Boudreau, M. D. and Beland, F. A, (2006). An evaluation of the biological and toxicological properties of Aloe Barbadensus (miller). Journal of Environmental Science and Health Part, 24: 103-154.

Cazander, G., Jukema, G.N and Nibbering, PH (2012). Clinical and developmental complement activation and inhibition in wound healing. African Journal of Pharmacy and Pharmacology, 3(6): 293 300.

Coleby-Williams, J. Cai, Y. Z. and Sun, M. (2008). Antioxidant activity of Betalins from plants of the Amaranthacea. Journal of Agriculture and Food Chemistry, 51: 2288-2294.

Ernest, E. (2009). Adverse effects of herbal drugs in dermatology. Journal of Chemical Microbiology and Infection, 9:236.

Faro, P. and Sereeramu (2004). Cultivation of Medical and Aromatic Crops. Revised Edn. Indian Orient Longman Publication. p 25.

Gong, M., Wang, E. and Chem, Y. (2002). Study on application of arbuscular mycorrhizas in growing seeding of Aloe vera. Journal of Chinese Medical Materials, 25(1): 1-3.
Gupta, V. K and Malhotra (2012). Pharmacological attribute of aloe vera. Revalidation through experimental and clinical studies Apr 33(2): 193-196.

Jamaica, G. (2010). Jamaica - gleaner.com. Harnessing the potential of our Aleo. Current Opinions in Plant Biology, 6:185190.

Hazara, B., Sentana, B. and Nripendranath, M. (2008). Antioxidant and free radicals scavenging activity of spondiaspinnata. BMC complement Altern Med.

Heinrich, M., Barnes, J. and Gibbons, S. (2008). Fundamentals of Pharmalognosy and Phytotheraphy, Churchill Livingstone, Edinburgh. pp 245-252.

Henry, R (2007). An updated review of aloe vera cosmetics and toiletries. Middle East Journal of Scientific Research, 3: 105108.

Leung, A.Y and Fosters, R (2009). Encyclopaedia of common natural ingredients used in food, drugs and Cosmetics, 78 (1): 35-39.

Marshal, J. M. (2010). Aleo vera gel: What is the evidence? The Pharmaceutical Journal, 24:360-362.

Ginseng, C. (2012). Traditional Australian medical plants: Screening for activity against human cancer cell lines. Journal of Australian Traditional Medicine and Sociology, 1:17-19.

Raynolds, T (2004). Neurohormetic phytochemicals: Low dose toxins that induce adaptive neuronal stress responses. Trends in Neuroscience, 29(11): 632-639.

Shuklas, S. (2008). Aleo vera has biodiesel potential. The Indian Express, 6:173-193.

United States Department of Health and Human Services (2010). Natural Institutes of health. National Centre for complementary and alternative medicine. Herbs at a glance: Aloe Vera International Journal of Integrative Biology, 6(2). 91-99. 
Vaibhar, V. (2008). India Experiments with farming medical plants. Brazilian Journal of Microbiology, 31: 247-256.

Yates, A. (2003). Yates Garden guide, Harper Collins Australia. Journal of the America Chemical Society, 125 (22): 6632-6633. 